\title{
"Leader-Employee" Power Distance Orientation and Employee's Voice: Based on the Mediating Effect Employee's Psychological Security
}

\author{
Chenyin Sun ${ }^{\mathrm{a}, 1}$, Hui Jin ${ }^{\mathrm{a}, \mathrm{b}}, \mathrm{Hu} \mathrm{Xu}^{\mathrm{a}}$ \\ ${ }^{a}$ School of Economics and Management, Jiangsu University of Science and Technology, \\ Zhenjiang \\ ${ }^{b}$ School of Management, Jiangsu University, Zhenjiang
}

\begin{abstract}
The purpose of this study is to explore the mechanism of employee's voice behavior from the perspective of "leader-employee" power distance orientation. The study found that: (1) employee's power distance orientation significantly negatively affects employee's psychological security and employee's voice behavior; (2) employee's psychological security significantly positively affects employee's voice behavior, and it plays a partial intermediary role between employee's power distance orientation and employee's voice behavior; (3) leader's power distance orientation significantly positively affects the employee power distance orientation, and significantly negatively affects the employee's psychological security and employee's voice behavior.
\end{abstract}

Key words: leader's power distance orientation; employee's power distance orientation; employee's psychological security; employee's voice behavior

\section{Introduction}

The era of knowledge economy is also an era of VUCA that is intertwined with volatile, uncertain, complex and ambiguous [1]. In the context of the new era, the market competition environment facing enterprises is changing rapidly, and the speed of technological innovation is also accelerating. And as an important way for employees to participate in organizational management, employee's voice behavior plays an important role in improving organizational operation efficiency and optimizing enterprise management mode[2][3]. However, employees are more willing to remain silent in the practice of enterprise management, even if employees find problems or improvements that can exist in the enterprise. Therefore, how to effectively dispel employees' concerns and promote employee's voice behavior is the focus of the business community and academia.

\footnotetext{
1 Corresponding Author: Chenyin Sun, Jin Guan building, room 101, the School of Economics and Management, Jiangsu University of Science and Technology, Zhenjiang 212003, China. Email address: sun6941@126.com.
} 
Previous studies have shown that employee's voice behavior is a kind of active behavior that is willing to express constructive opinions. This behavior is not only to change the personal working situation, but also to help the organization improve and promote the development of the organization [4]. At the same time, it's also a risky behavior. Employees often worry that their "fallacy" and "dissent" will lead to troubles such as "offending leadership", career and interpersonal problems [5]. This is especially true in Chinese companies with prominent centralization characteristics (ie, the concentration of managers' power). It can be inferred from this that the individual's view on the power system may have an impact on employee's voice. That is, the individual power distance orientation (cognition of power distribution) is closely related to employee's voice behavior [6]. However, it has not received much attention from the previous studies. And according to the interpersonal interdependence theory, employee's individual behaviors or behavioral intentions will be influenced by leader's behavior traits (surrounding groups). So we decided to explore the mechanism of employee's voice behavior from the perspective of the power distance orientation of the "leader-employee" dual subject.

Therefore, the purpose of this study is to answer two questions: (1) How does the employee's power distance orientation at the individual level affect employee's voice behavior? (2) How does the leader's power distance orientation at the team level affect the employee's power distance orientation and employee's voice behavior at the individual level?

\section{Theoretical Review and Hypothesis}

\subsection{Hypothesis at the individual level}

- Employee's Power Distance Orientation and Employee's Voice Behavior

Employee's power distance orientation refers to the degree to which individuals can accept the unequal distribution of power or the different levels of power within the organization[7][8]. It reflects employees' differentiated cognition of unequal power distribution in the organization, and such cognition will affect their behaviors in the organization. Employees with high power distance orientation believe that the power and status gap between them and the leaders is reasonable and they should obey the leader's instructions. However, employees with low power distance orientation are different. They will more likely to interact with leaders fairly and freely, and will often express their ideas to leaders more actively[9][10][11]. According to the self-consistency theory, individuals strive to maintain consistency in their beliefs, attitudes, and behaviors, whether this belief is positive or negative[12]. It can be inferred that when the power distance orientation of employees is high, they will have an attitude of unconditional obedience and reverence to their leaders. At this time, employees' behavior proposing their own suggestions to the leaders is contrary to their own cultural values and beliefs, so employees' voice behavior will be suppressed. On the contrary, when the employee's power distance orientation is low, they will hope to establish a close and friendly relationship with the leader, and they will be more willing to exchange their thoughts and opinions on the development of the organization with the leader. At this point, the employee's voice behavior will be stimulated. Therefore:

H1: Employee's power distance orientation negatively affects employee's voice behavior 
- Employee's Power Distance Orientation and Employee's Psychological Security

The individual's psychological security comes from own internal security needs, and it is manifested as the individual's subjective perception of external environmental risks[13][14]. Evolutionary psychology believes that any stimulus that conflicts with individual expectations will consciously awaken the individual's psychological defense and put the individual in a lower psychological security environment[15]. And in this study, we believe that the higher the power distance orientation of employees at the edge of power, the more sensitive and concerned they are to the differences in power, status, and rank within the organization. As the saying goes, "Man struggles upwards; water flows downwards". As a result, the employees with high power distance orientation are more likely to develop a desire for high power status, which is far from its actual role of "Poor men's words have little weight". This contradiction between psychological expectations and reality will make them to have lower psychological security. On the contrary, the employees with low power distance orientation don't agree with unequal power distribution. This recognition determines that their desire for power and status is low, and there is no conflict with their actual status. At this time, employees' level of psychological defense will be reduced, thereby forming a higher sense of psychological security. Therefore:

H2: Employee's power distance orientation negatively affects employee's psychological security

- Employee's Psychological Security and Employee's Voice Behavior

Employee's psychological security is their perception of risks related to their careers, self-image and status in the process of interacting with leaders [13][16]. And this cognition will make employees have a psychological expectation about whether their behavior is safe or whether it will lead to negative consequences. When employees have a high level of psychological security, they will have positive psychological expectations, which will reduce their defense against others. But when employees' psychological security is low, they will have negative psychological expectations, and then strengthen their own alertness. From this we speculate that employees with a high level of psychological security will have a low level of psychological defense in their interactions with leaders. As a result, they are more likely to show positive interactive actions to leaders, and it is easier to express their true self freely[17]. That is, employee's psychological security will positively promote their voice behavior. Liang and Farh (2008) pointed out that if the company want to improve the enthusiasm of employees' voice behavior, they must improve their psychological security[18]. Therefore:

H3: Employee's psychological security positively affects employee's voice behavior

\subsection{Hypothesis at the team Level}

- Leader's Power Distance Orientation and Employee's Power Distance Orientation

Social learning theory believes that others (especially "foretype") in the surrounding environment are important sources of information for individual observation and learning, so individuals will consciously or unconsciously shape their social attitudes and behaviors by observing and imitating others. And the leaders are often the main objects observed and imitated by employees in organization[19]. The characteristics of leaders (such as cultural value orientation) will gradually trickle down to employees by their daily management behaviors, exerting a profound influence on 
the characteristics of employees (such as cultural value orientation) imperceptibly. Deducing to this study, leaders with high power distance orientation often show an authoritarian style, and tend to build an "authoritative" image in front of employees to show their status cannot be challenged. When employees perceive such a strong signal, they tend to adapt themselves to the management style of their superiors through observation and imitation, thus gradually forming a higher power distance orientation. Similarly, it can be speculated that leaders' low power distance orientation will also promote a low power distance orientation for employees in this way. Therefore:

H4: Leader's power distance orientation positively affects employee's power distance orientation

\section{- Leader's Power Distance Orientation and Employee's Psychological Security}

Previous studies have shown that employee's psychological security may be affected by organizational situations and leadership behaviors [20]. In this study, leaders with high power distance orientation have a strong sense of hierarchy. Therefore, they are very concerned about the power and status gap between superiors and subordinates, and believe that subordinates should respect and obey themselves[21]. When employees realize this, they will consciously keep their distance and be cautious in their interactions with leaders, so as to avoid letting leaders think that their "authority" is offended and thus cause trouble for employees themselves. At this time, employees' uncertainty about the risks of their environment (e.g work environment, interpersonal environment) increases, and thus they are in a lower psychological security environment. On the contrary, leaders with low power distance orientation have positioned their role in power relationships as friends and partners that are beyond the constraints of hierarchical systems, so they will choose to actively close the relationship with employees to show their friendliness. When employees receive the "olive branch" from the leader, they will return to the leader with friendship and trust for emotional exchange. At this time, employees' perception of risks related to their own development, professional image, etc. will also be reduced, thereby gaining a higher sense of psychological security. Therefore:

H5: Leader's power distance orientation negatively affects employee's psychological security

- Leader's Power Distance Orientation and Employee's Voice Behavior

The value-based leadership theory believes that leaders will bring their cultural values into management, and hope that their subordinates can resonate with them so as to improve the effectiveness of their leadership behaviors. For leaders with high power distance orientation, they often emphasize power concentration and use of power to control employees. They are confident in their management ideas and methods, and believe that it is reasonable for subordinates to obey their management. This kind of cultural values often makes leaders show authoritative and serious leadership style in daily management. What's more, the employee's voice behavior in this study belongs to a bottom-up risky feedback behavior. Therefore, when employees feel the leader's power distance orientation through the leadership management style, they will choose to be silent because of the risk (e. g offending the leader) of their voice behavior. In contrast, leaders with low power distance tend to ignore the hierarchy gap between superiors and subordinates. At this time, they are willing to communicate with employees, and also tolerate and encourage employee's voice behavior. When employees think that their opinions and ideas are advocated and recognized by leaders, employees are more willing to conduct voice behavior. Therefore: 
H6: Leader's power distance orientation negatively affects employee's voice behavior

The theoretical model proposed in this study is shown in Figure 1.

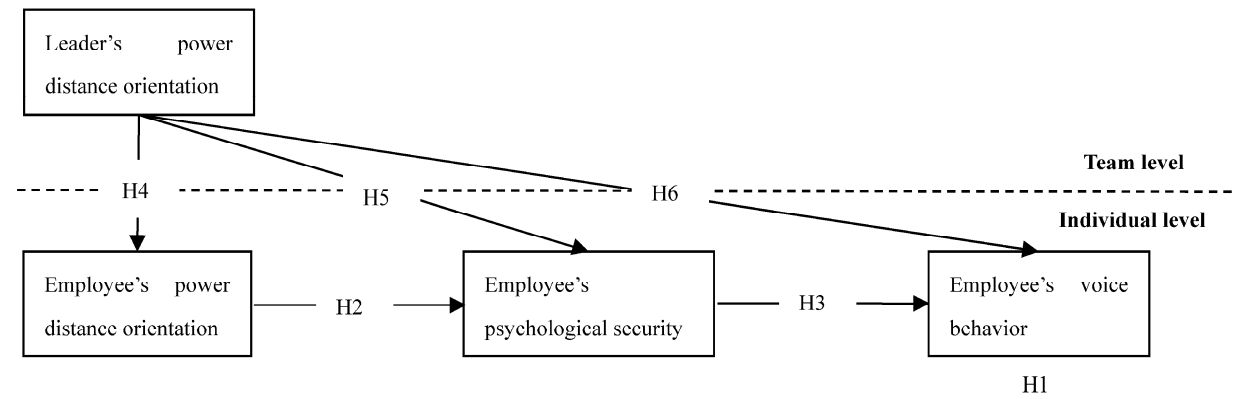

Figure.1 Theoretical model

\section{Research Design}

\subsection{Methods}

This study uses electronic questionnaires for online data collection. And the questionnaire is divided into two versions: a leadership questionnaire (a survey of leader's power distance orientation at the team level) and an employee questionnaire (a survey of employee's power distance orientation, employee's psychological safety, and employee's voice behavior at the individual level). In the end, 338 questionnaires were effectively recovered, including 286 questionnaires of employees and 52 questionnaires of leaders.

The sample statistics of employees showed that male accounted for $53.846 \%$ and female accounted for $46.154 \%$. In terms of age, 26-30 years old accounted for $32.867 \%$, 31-35 years old accounted for $25.175 \%$, and 36-40 years old accounted for $16.084 \%$. In addition, bachelor's and master's degrees are the main academic qualifications, accounting for $49.301 \%$ and $35.664 \%$ respectively. In terms of working years, 3 years and below accounted for $28.322 \%$, and $4-6$ years accounted for $40.559 \%$.

The sample statistics of the leaders show that male account for $63.462 \%$ and female account for $36.538 \%$. In the age structure, the majority are $31-35$ years old, accounting for $48.077 \%$, and followed by $26-30$ years old with $23.077 \%$, and $36-40$ years old with $19.231 \% \%$. The academic structure is still dominated by undergraduate and master degrees, with masters accounting for $51.923 \%$ and undergraduates accounting for $36.538 \%$. In terms of working years, 7-9 years accounted for $50.000 \%$, followed by $4-6$ years accounted for $34.615 \%$. What's more, the average team size is 5.306.

\subsection{Research Tools}

The scales selected in this study are derived from the maturity scales in the existing research, and have been partially revised in accordance with the specific research context of this study. 
- Power distance orientation. The measurement of leader's power distance orientation and employee's power distance orientation in this study both adopt the single-dimensional scale developed by Dorfman and Howell[22]. And the finally measured Cronbach'a $=0.886$.

- Employee's psychological security. The measurement of employee's psychological security in this study is derived from the study of Carmeli[23]. And the finally measured Cronbach' $a=0.878$.

- Employee's voice behavior. In this study, the scale of employee's voice behavior measurement derived from Liang and Farh[18]. And the measured Cronbach'a = 0.922 .

- Control variables. Referring to previous studies[2][25][26], this study mainly selects gender, age, education, and working years as individual-level control variables, and selects gender, age, education, working years, and team size as team-level control variables.

\section{Data Analysis and Results}

\subsection{Data Quality Analysis}

- Reliability. The Cronbach'a of all the variables in this study range from 0.878 to 0.972 and the $\mathrm{CR}$ (combined reliability) range from 0.878 to 0.922 , which indicates that the measurement reliability is good. (Table 1)

- Validity. The AVE of each variable is between 0.545 and 0.596 , and the square root of the AVE of each variable (data in the diagonal brackets in Table 1) is greater than correlation coefficients among variables, which indicating that the aggregation validity and discrimination validity are good (Table 1). At the same time, the results of CFA (confirmatory factor analysis) show that the four-factor model has the best fitting effect $(\chi 2 / \mathrm{df}=1.296, \mathrm{SRMR}=0.036, \mathrm{RMSEA}=0.041$, $\mathrm{GFI}=0.929$, NFI $=0.942, \mathrm{TLI}=0.980, \mathrm{CFI}=0.971)$.

- Common method bias. We conducted a principal component analysis according to the Harman's single factor test, and the largest common factor explained $34.533 \%$ of the total variance $(62.742 \%)$, and the common method bias is within an acceptable range.

Table 1. Analysis of reliability and validity of study variables

\begin{tabular}{lccccccccc}
\hline \multicolumn{1}{c}{ Variables } & $\boldsymbol{\alpha}$ & $\mathbf{C R}$ & AVE & Mean & SD & $\mathbf{1}$ & $\mathbf{2}$ & $\mathbf{3}$ & $\mathbf{4}$ \\
\hline $\begin{array}{l}\text { Leader's power distance } \\
\text { orientation }\end{array}$ & 0.886 & 0.893 & 0.582 & 2.219 & 0.766 & $(0.763)$ & & & \\
$\begin{array}{l}\text { Employee's power } \\
\text { distance orientation }\end{array}$ & 0.886 & 0.887 & 0.570 & 2.427 & 0.928 & $0.201^{* *}$ & $(0.755)$ & \\
$\begin{array}{l}\text { Employee's psychological } \\
\text { security }\end{array}$ & 0.878 & 0.880 & 0.596 & 3.597 & 0.784 & $0.146^{* *}$ & $-0.177^{*}$ & $(0.772)$ \\
$\begin{array}{l}\text { Employee's voice } \\
\text { behavior }\end{array}$ & 0.922 & 0.923 & 0.545 & 3.602 & 0.682 & $0.274^{* *}$ & $-0.153^{* *}$ & $0.470^{* *}$ & $(0.738)$ \\
\hline
\end{tabular}

Note: * represents $\mathrm{p}<0.05, * *$ represents $\mathrm{p}<0.01$. The numbers in parentheses on the diagonal are the square root of AVE. 


\subsection{Regression analysis}

This study uses HLM analysis software to conduct a multi-line model analysis on the relationship between variables. (1)The results of the statistical analysis of the relationship between variables at the individual level show that: employee's power distance orientation $(\mathrm{r}=-0.121, \mathrm{P}<0.01)$ has a significant negative effect on employee's voice behavior (Model 2), which indicates that H1 is supported; employee's psychological security $(\mathrm{r}=0.408, \mathrm{P}<0.001)$ has a significant positive effect on employee's voice behavior (Model 3), which indicates that H3 is supported; employee's power distance orientation $(\mathrm{r}=-0.122, \mathrm{P}<0.05)$ has a significant negative effect on employee's psychological security, which indicates that $\mathrm{H} 2$ is supported. (2)The analysis results of the cross-level influence of the leader's power distance orientation at the team level show that: leader's power distance orientation $(\mathrm{r}=0.250, \mathrm{P}$ $<0.001)$ has a significant positive effect on the employee's power distance orientation, which indicates H4 is supported; leader's power distance orientation ( $\mathrm{r}=-0.150, \mathrm{P}$ $<0.01$ ) has a significant negative effect on employee's psychological security, which indicates H5 is supported; leader's power distance orientation $(\mathrm{r}=-0.267, \mathrm{P}<0.001)$ has a significant negative effect on employee's voice behavior, which indicates H6 is supported.

In addition, this study uses Bootstrap test for further analysis. The analysis results show that the indirect effect of employee's power distance orientation on employee's voice behavior is -0.044 , and the confidence interval of $0.95[-0.089,-021]$ doesn't include 0 , indicating that the indirect effect is significant. This confirms that employee's psychological security indeed has a mediating effect between employee's power distance orientation and employee's voice behavior.

\section{Conclusion}

\subsection{Theoretical and practical implications}

The main research conclusions and practical management implications of the study are as follows:

Employee's power distance orientation significantly negatively affects employee's voice behavior. This conclusion not only confirms the inhibitory effect of power distance orientation on employee's voice behavior[27], but also indicates that the main effect of employee's power distance orientation on employee's voice behavior exists objectively. Therefore, in order to promote employee suggestions, it is recommended that enterprises should take some intervention measures such as advocating and focusing on creating a harmonious and fair, equal and unity organizational culture atmosphere, or promote inculcation of team awareness during employee training to cultivate employee's low power distance orientation. On the other hand, managers can adopt flexible management methods to encourage employees to actively participate in the management process, thereby fostering their sense of ownership and stimulating employee's voice behavior.

Employee's psychological security plays a partial intermediary role between employee's power distance orientation and employee's voice behavior at the individual level. On the one hand, this conclusion echoes the previous research on employee's psychological security and employee's voice behavior [3][29], and also finds that 
individuals' power distance orientation can have an effect on their psychological security. Based on this conclusion, it is recommended that managers should pay attention to the psychological state and spiritual demands of employees. Enterprises can enhance the emotional connection and interpersonal trust of employees by organizing collective activities and other methods, thereby enhancing the employees' psychological security and promoting their voice behavior.

When investigating the cross-level influence of leader's power distance orientation on employees, we found that: First, Leader's power distance orientation has a significant positive effect on employee's power distance orientation. Second, Leader's power distance orientation has a significant negative effect on employee's psychological security and employee's voice behavior. This not only confirms that the cultural values and organizational behaviors of leaders have a "trickle effect" on employees' cultural values and behaviors[29], but also illustrates the negative effects of the high-power distance orientation of leaders on employees. This reminds enterprises to take some necessary measures to weaken the negative effect of power distance orientation, such as focusing on creating a united, harmonious, equal and friendly organizational atmosphere. Moreover, we should also attach importance to cultivating the concept of collectivism of leaders to help leaders form low power distance orientation and change management styles. At the same time, enterprises should also consider the power distance orientation level test as one of the assessment indicators for talent training and selection.

\subsection{Limitations and future research}

The theoretical contribution of this study mainly lies in: (1) This study takes power distance orientation as an independent variable to explore how it affects employee's voice behavior. This conclusion not only confirms that power distance orientation as a representative variable of individual cultural value orientation is an important variable for interpreting employee's voice behavior, but also provides a reference for follow-up exploration about other cultural value orientation variables and employee's voice. (2) This study finds that employee's psychological security can mediate the relationship between employee's power distance orientation and employee's voice behavior. This provides a theoretical support for explaining the "black box" of the relationship between individual power distance orientation and employee's voice behavior. Moreover, it provides some ideas for further research about the influence mechanism of power distance orientation on employee's voice behavior. (3) This study takes into account the two-way perspective of leaders and employees. While considering the influence of employee's power distance orientation on their voice behavior, this study further explores the cross-level effect of leader's power distance orientation, and provides useful supplements for the study of leadership behavior theory and employee's voice behavior.

Certainly, this study also inevitably has limitations: (1) The sample collection of this study is concentrated in the same time period, and the sample coverage is limited, which may affect the external validity of the research conclusions of this study. Therefore, it is suggested that subsequent research can optimize the multi-period collection and wide coverage of samples to test the universality of the conclusions in this study. (2) Although this study finds that employee's psychological security will mediate the effect of employee's power distance orientation on employee's voice behavior, it is unknown whether employee's psychological security exists as a 
mediation in cross-level effect. We suggest that it can be further explored and explained in subsequent related research.

\section{References}

[1] Seow P S, Pan G, Koh G. Examining an Experiential Learning Approach to Prepare Students for the Volatile, Uncertain, Complex and Ambiguous (VUCA) Work Environment [J]. The International Journal of Management Education. 2019; 17(1): 62-76.

[2] Li Y.P., Shi Y., Mao Y.B. Empowering Leadership and Employee Voice: the Mediating Role of Psychological Ownership. Science \& Technology Progress and Policy. 2018; 35(3): 140-145.

[3] Wang M.H., Gong T.F., Wang D.D. The Effects of Spiritual Leadership on Employee's Voice Behavior: Mediating Effects of Organizational Climate and Psychological Safety. Journal of Henan University (Social Science). 2017; 57(6): 115-122.

[4] Vandyne L, Cummings L L, Parks J M L. Extra-role behaviors-in pursuit of construct and definitional clarity (a bridge over muddied waters). Research in Organizational Behavior. 1995; 17:215-285.

[5] Niu X.Y., Ding Y.Q., Wang L. Effect of Inclusive Leadership on Enterprise Business Model Innovation: From the Perspective of Employees' Voice. Forecasting. 2019; 38(1): 15-21.

[6] Zhan X.H., Su X.Y. Research on the Impact of Personal Reputation on Voice Endorsement: The Moderating Effect of Power Distance. Science of Science and Management of S.\& T. 2019; 40(8): 126-140.

[7] Moorhead, G. \& R. W. Griffin. Organizational Behavior. Boston: Houghton Mifflin Company, 1989.

[8] Hofstede G. The cultural relativity of organizational practices and theories. Journal of International Business Studies. 1983; 14(2):75-89.

[9] Bao Y., Liao J.Q. Power Distance: A Literature Review and Prospect. Management Review. 2019; 31(3):179-192.

[10] Lian H, Ferris D L, Brown D J. Does power distance exacerbate or mitigate the effects of abusive supervision? It depends on the outcome. Journal of Applied Psychology. 2012; 97(1):107-123.

[11] Liu H.Y., Liu S.M., Wang H. The Influence of Leader-Follower Value Congruence in Power Distance on Follower's Performance and Its Mechanism. Nankai Business Review. 2016; 9(5):55-65.

[12] Lu Y., Peng Z.L., Yu L.N. Study on the Influence of Empowering Leadership on Voice Behavior. Industrial Engineering and Management. 2017; 22(3): 159-165.

[13] Liang X.J., Yu G.L., Fu B. How does Supervisor-subordinate Guanxi Affect Voice? Psychological Safety and Face Concern as Dual Mediators. Management Review. 2019; 31(4):128-137.

[14] Kahn W A. Psychological conditions of personal engagement and disengagement at work. Academy of Management Journal. 1990; 33(4):692-724.

[15] Miron-Spektor E, Efrat-Treister D, Rafaeli A, et al. Others' anger makes people work harder not smarter: The effect of observing anger and sarcasm on creative and analytic thinking. Journal of Applied Psychology, 2011; 96(5):1065-1075.

[16] Wang Y.Y., Zhang L. How Psychological Resilience Influence Employees' Creativity: The Role of Psychological Safety and Creative Self-Efficacy. Psychological Science. 2018; 41(1):118-124.

[17] Javed B, Naqvi S M M R, Khan A K, et al. Impact of inclusive leadership on innovative work behavior: The role of psychological safety. Journal of Management \& Organization. 2017; 25(1):1-20.

[18] Liang J, Farh J L. Promotive and prohibitive voice behavior in organizations: A two-wave longitudinal examination// third conference of the international association for Chinese management research, Guangzhou, China. 2008: 19-22.

[19] Li G.Q., Xi Y.M., Liu H.X. Research on the Effect Mechanism of Transformational Leadership on Knowledge Sharing. Science of Science and Management of S.\& T. 2014; 35(9):48-58.

[20] Zou Y.C., Yin T.B. A Multi-level Perspective on the Review of Psychological Safety. Human Resources Development of China. 2017(4):66-75.

[21] Hu J, Erdogan B, Jiang K, et al. Leader humility and team creativity: The role of team information sharing, psychological safety, and power distance. Journal of Applied Psychology. 2018; 103 (3):313-323.

[22] Dorfman P W, Howell J P. Dimensions of national culture and effective leadership patterns: Hofstede revisited. Advances in international comparative management. 1988; 3(1):127-150.

[23] Carmeli A, Reiter-Palmon R, Ziv E. Inclusive leadership and employee involvement in creative tasks in the workplace: The mediating role of psychological safety. Creativity Research Journal. 2010; 22(3):250-260. 
[24] Li Z.B., Wang M.H. The Impact of Authoritarian Leadership on Employee's Silence Behavior: A Study of a Moderated Mediating Effect. Studies of Psychology and Behavior. 2018; 16(5): 713-719.

[25] Zhong L.F., Meng J., Gao L. Ethical Leadership and Employee Creative Performance: The Mediating Role of Social Exchange and the Moderating Role of Power Distance Orientation. Management World. 2019; 35(05): 149-160.

[26] Xu Z.T., Li X.M., Luo J.L., Qu Y.Y. Making Personal Sacrifices for the Public Voice: The Multi-Level Relationship between Self-Sacrificial Leadership and Employee Voice Behavior. Science of Science and Management of S.\& T. 2019; 40(8): 141-157.

[27] Hu J, Judge T A. Leader-team complementarity: Exploring the interactive effects of leader personality traits and team power distance values on team processes and performance. Journal of Applied Psychology. 2017; 102(6):935-955.

[28] Kwak W J, Shim J H. Effects of Machiavellian ethical leadership and employee power distance on employee voice. Social Behavior and Personality: An International Journal. 2017; 45(9):1485-1498.

[29] Li J. Yang Z. A Study on the Influence of Extroverted Personality Traits on Speaking Behaviors: The Cross-level Moderating Role of Authoritarian Leadership. Academia Bimestris. 2017(6): 129-134. 